\title{
Potential Impacts of Food and it’s Processing on Global Sustainable Health
}

\author{
Sadam DV Satyanarayana ${ }^{1 *}$, Pavan Kumar Pindi², Amit singh ${ }^{3}$, Dattatreya A $^{4}$ and Aditya $\mathbf{G}^{5}$ \\ ${ }^{1}$ Department of Microbiology, Palamuru University, Mehbub Nagar, AP, India \\ ${ }^{2}$ Accociate Proffessor (H.O.D), Department of Microbiology, Palamuru University, Mehbub Nagar, AP, India \\ ${ }^{3}$ Amit Singh, Department of Biotechnology, Guru Ghasidas Vishwavidyalaya, Bilaspur, Chhattisgarh, India \\ ${ }^{4}$ Department of Microbiology, GITAM Institute of Sciences, GITAM University, Andhrapradesh, India \\ ${ }^{5}$ Department of Biotechnology, Pepsi Co India Ltd., Kanpoor, India
}

\begin{abstract}
Processed foods or modified raw foods made by the addition of hormones, additives, preservatives, other chemical or heat treatments that alter the natural healthy enzymes, fatty acids, vitamins and minerals. In comparison to raw and unprocessed foods processed foods are usually safer, durable and with high level of bioactivity of nutrients. At present, the advancement in food processing methods and techniques is necessary to meet the challenges of food security \& safety, nutrition demand and availability of food at the global level. Therefore, the present review comprises the information on different aspects of food processing and the effects of food products on sustainable health of humans by means of several examples of processed foods with change in their nutritional values before and after processing. It is also a well known fact that understanding the chemical basis, structure and texture of foods to be processed can help processing industries to develop novel food products. In support of this fact this article also deals with the future trends and possible changes in food processing industries with the combination of traditional and modern technologies to get the desired nutritional and other qualities in food.
\end{abstract}

Keywords: Food processing; Processed foods; Potential impact; Bioactivity; Human health; Food security; Food Safety; Nutrition

\section{Introduction}

Nutrition and nutritional factors are widely considered to be crucial for health and well-being of the humans [1,2]. The well documented evidences from epidemiological studies indicate several degenerative diseases [3], cardiovascular diseases [4] and some types of cancers [5] are linked with diet and nutrition uptake and its regulations. All these diet-related problems are likely to change eating habits, processing technologies, and products [5,6]. Many beneficial and detrimental health effects of specific nutrients present in foods are well known to us and the total amount of a nutrient may depend upon its "availability" for absorption in the gut is in many cases quite uncertain or varies for the same food depending on the food processing conditions, presence of other components, and so on [7].

It was previously reported that the ingested nutrient fraction used by organism is obviously of major importance and several factors influence its availability like chemical state of the nutrient, its release from the food matrix, possible interactions with other food components, presence of suppressors or cofactors, formation of stable compounds that are slowly metabolized etc. These findings have created a new perspective concerning the potentiality of processed diet in preventing serious diseases in the future and also demonstrated that however in the case of certain nutrients, the state of the matrix of natural foods or the microstructure of processed foods may favor or hinder their nutritional response in vivo.

For this the global nutrition rich food demand depends on processed food products because processing is expected to affect content, activity and bioavailability of bioactive compounds. Some examples of processed foods are: delicate preparation of deadly fugu fish [8] or preparing space food for consumption under zero gravity jams and jellies made by heat treating fruit pulp and filtrate with sugar so yield semi solid spreads [8] etc. However, the health-promoting capacity of food products strictly depends on their processing history.
In present scenario, food Processing is being used as a major way to enhance human nutrition: to improve global food security by enhancing the nutritional composition of foods and its availability, especially for locally grown and familiar foods in the developing world, that would interest both the developed and developing worlds [9].

On industrial scale, environment friendly advance procedures with minimal loss of bioactivities are highly desirable for the food processing in foods industries [10]. High-quality processed food products that meet food safety [11] regulations and with high essential nutrient contents will offer potential benefits to human health. In this demanding era, the advancement in research is necessary to meet the challenge of food security and availability of food that is not only for feeding purpose but also rich in nutrition, because it is associated with well development of human resources in any country and it directly affects their contributions to the world [11,12]. Therefore, the aim of this review is to provide the recent information about the effects of food products on health at global level by means of several examples of processed foods with their nutritional contents before and after processing.

\section{Unprocessed Food, its Nutritional Quality and Effect on Human Health}

Nutrient availability to people is primarily determined by the output of foods produced from agricultural systems and foods

*Corresponding author: Sadam DV Satyanarayana, Department of Microbiology, AQJ PG College, Andhra University, Visakhapatnam, Tel: +91-9533801433; E-mail: sadams188@yahoo.com

Received November 22, 2011; Accepted December 25, 2011; Published December 28, 2011

Citation: Satyanarayana SDV, Pavan Kumar P, Amit S, Dattatreya A, Aditya G (2012) Potential Impacts of Food and it's Processing on Global Sustainable Health. J Food Process Technol 3:143. doi:10.4172/2157-7110.1000143

Copyright: (C) 2012 Satyanarayana SDV, et al. This is an open-access article distributed under the terms of the Creative Commons Attribution License, which permits unrestricted use, distribution, and reproduction in any medium, provided the original author and source are credited. 
obtained from plants provide most of the nutrients that feed the developing world [13]. As a result of overpopulation, many global food systems are not able to provide enough micronutrients to assure adequate micronutrient intakes for all people. If agricultural systems fail to provide enough products containing adequate quantities of all essential nutrients during all seasons, this results in dysfunctional food systems that cannot support healthy lives. Unfortunately, this is the case for many agricultural systems in most of the developing nations in the Globe [14].

This can results in an increasing prevalence of micronutrient deficiencies (e.g., iron deficiency, vitamin A, and iodine deficiency disorders) that now afflicts over three billion people globally mostly among infants and children in developing countries. More over Human epidemiologic and animal studies have shown that diet plays an important role in cancer development [15]. The consequences of micronutrient malnutrition are profound and alarming for human existence [16].

\section{The concept of nutrition transition}

During the evolutionary period diet and nutritional status in humans have undergone a sequence of major shifts in their characteristics that lead to broad food usage patterns and corresponding nutrition-related disease [17]. The concept of the nutrition transition focuses on large shifts in diet and its activity patterns, especially their structure and overall composition [18]. These changes are reflected in nutritional outcomes, such as changes in average stature and body composition. Furthermore, dietary and activity pattern changes are paralleled by major changes in health status and by major demographic and socioeconomic changes [18].

Eating patterns of different countries varies (for example Chickpea is a staple food crop in some tropical and subtropical countries) [19] and their shifts, in particular, seem to be specific to different regions and sets of countries. In the higher-income countries, increased portion sizes, away-from-home food intake, and snacking are eating pattern shifts that accompany these changes. Water and milk appear to be replaced by calorically sweetened beverages [20-22]. Dozens of studies document these shifts in the developed countries, and few studies document these same shifts in other countries also, where concern for these shifts is greatest [18].

There are marked differences between urban and rural eating patterns; particularly the consumption of food prepared away from home is leading to decline in under nutrition accompanied by a rapid increase in obesity [23]. Other issues includes the metabolic efficiencies that served well in conditions of fetal undernutrition become maladaptive with overnutrition, leading to the development of abnormal lipid profiles, altered glucose and insulin metabolism and obesity [24].

\section{Global food demand or human nutrition crisis?}

Every human require nutrients to meet their metabolic needs, inadequate consumption of even one of this nutrient will result in adverse metabolic disturbances leading to sickness, poor health, impaired development in children as well as in adults [25]. The required daily requirement of nutrients for each life stage was given in table 1 .

* Relative to adult requirements for those 19-50 years of age (and on a per-kg basis for macronutrients). ** Applies only to individuals under age 18 .

\begin{tabular}{|c|c|}
\hline Life Stage & Change in Nutrient Needs \\
\hline Pregnancy* & $\begin{array}{l}\text { Increased requirements: energy [27], protein, essential fatty } \\
\text { acids, vitamin } A \text {, vitamin } C, B-v i t a m i n s \\
\left(B_{1}, B_{2}, B_{3}, B_{5}, B_{6} \text {, }\right. \\
B_{12} \text {, folate, choline } \& \text { calcium, phosphorus }{ }^{* *}, \text { magnesium, } \\
\text { potassium, iron, zinc, copper, chromium, selenium, iodine, } \\
\text { manganese, molybdenum }\end{array}$ \\
\hline Lactation* & $\begin{array}{l}\text { Increased requirements: vitamins } A, C, E \text {, all B-vitamins, } \\
\text { sodium, magnesium }^{\star *} \\
\text { Decreased requirements: iron }\end{array}$ \\
\hline $\begin{array}{l}\text { Infancy, } \\
\text { childhood* }\end{array}$ & $\begin{array}{l}\text { Increased requirements: energy, protein, essential fatty } \\
\text { acids }\end{array}$ \\
\hline Adolescence $^{*}$ & $\begin{array}{l}\text { Increased requirements: energy, protein, calcium, } \\
\text { phosphorus, magnesium, zinc (females only) }\end{array}$ \\
\hline $\begin{array}{l}\text { Early adulthood } \\
\text { (ages 19-50) }\end{array}$ & $\begin{array}{l}\text { Increased requirements for males compared with } \\
\text { females: vitamins } \mathrm{C}, \mathrm{K} ; \mathrm{B}_{1}, \mathrm{~B}_{2}, \mathrm{~B}_{3} \text {, and choline; magnesium, } \\
\text { zinc, chromium, manganese } \\
\text { Increased requirements for females compared with } \\
\text { males: iron }\end{array}$ \\
\hline $\begin{array}{l}\text { Middle age (ages } \\
51-70)^{*}\end{array}$ & Increased requirements: vitamin $B_{6}$, vitamin $D$ \\
\hline $\begin{array}{l}\text { Elderly (age } \\
70+)^{\star}\end{array}$ & $\begin{array}{l}\text { Increased requirements: vitamin D } \\
\text { Decreased requirements: energy; iron (females only) }\end{array}$ \\
\hline
\end{tabular}

Table 1: The changes in daily requirements of nutrient needs according to age [26].

A growing consensus of the world's scientists, as well as analysts, following agriculture system, are convinced we are moving towards food and related nutrition crisis of unprecedented scale. According to Oxfam International report, "The warning signs are clear. We have entered an age of crisis: of food price spikes and oil price hikes; of scrssambles for land and water; of creeping, insidious climate change. The 2008 spike in food prices pushed some 100 million people into poverty" [28].

\section{Malnutrition and food insecurity}

According to a new study by UK researchers, more than 200 million children younger than 5 in developing countries do not reach their full intellectual potential because of malnutrition and lack of social and cognitive stimulation [29]. Grantham-McGregor and colleagues has reported that the total frequently stunt children's growth have a major portion of the population living in absolute poverty. They also stated that 219 million of 559 million children fail to reach normal cognitive development, which definitely affect their learning ability and career in life [30]. They emphasized the malnutrition, especially iron and iodine deficiency--is largely to blame for children's failure to reach full intellectual potential. However, an additional problem is that parents often fail to stimulate their children's intellect with learning activities that spur brain development [30].

\section{A few salient facts}

- An estimated 250 million preschool children are vitamin A deficient and it is likely that in vitamin $A$ deficient areas a substantial proportion of pregnant women is vitamin A deficient.

- An estimated 250000 to 500000 vitamin A-deficient children become blind every year, half of them dying within 12 months of losing their sight.

-WHO [31]

Food security can be defined as "all people at all times having both physical and economic access to the basic food they need" [32]. For approximately 2 billion people throughout the world, this security is 
anything but guaranteed. Food security is a complicated issue that is susceptible to many forces. Insecurity results from climate change, urban development, population growth and many reasons that are interconnected and rarely confined by borders. Food insecurity is an issue of global importance [32].

\section{The Issue of Better Food with Rich Nutrient Content i.e. Processed Food}

Nutrient required for normal body functioning that either cannot be synthesized by the body is known as essential nutrient and thus must be obtained from a dietary source [33]. Essential nutrients are also defined by the collective physiological evidence for their importance in the human diet. Major groups of essential nutrients in human diet are essential fatty acids, essential amino acids, vitamins [34] and dietary minerals [35].

\section{Essential fatty acids}

The term "Essential Fatty Acid" refers to fatty acids required for biological processes, and not those that only act as fuel [36]. Only two EFAs are known for humans: alpha-linolenic acid (an omega-3 fatty acid) [37] and linoleic acid (an omega-6 fatty acid). Other fatty acids that are only "conditionally essential" include gamma-linolenic acid (an omega-6 fatty acid), lauric acid (a saturated fatty acid), and palmitoleic acid (a monounsaturated fatty acid) [37]. Essential fatty acids also play an important role in the life and death of cardiac cells [38].

\section{Essential amino acids}

The essential amino acids are phenylalanine, valine, threonine, tryptophan, isoleucine, methionine, leucine, lysine, and histidine. Additionally, cysteine (or sulphur-containing amino acids), tyrosine (or aromatic amino acids), and arginine are required by infants and growing children [39]. At the level of the ribosome, the cells of eukaryotes require up to 21 different amino acids for protein synthesis [39]. A shortfall of any one of these amino acids would thus be a limiting factor in protein synthesis. However, eukaryotes can synthesize some of these amino acids from other substrates. Consequently, only a subset of the amino acids used in protein synthesis is essential nutrients [39]

\section{Vitamins}

Vitamins are classified by their biological and chemical activity thus each "vitamin" refers to a number of vitamer compounds that all show the biological activity associated with a particular vitamin [6]. Vitamers by definition are convertible to the active form of the vitamin in the body, and are sometimes inter-convertible to one another, as well. Vitamins have diverse and specific biochemical functions [40]. Some have hormone-like functions as regulators of mineral metabolism (e.g., vitamin $\mathrm{D}$ ), or regulators of cell and tissue growth and differentiation (e.g., some forms of vitamin A). Others function as antioxidants (e.g., vitamin $\mathrm{E}$ and sometimes vitamin $\mathrm{C}$ ). [41] The largest number of vitamins (e.g., B complex vitamins) functions as precursors for enzyme cofactors that help enzymes in their work as catalysts in metabolism [42].

\section{Dietary minerals}

Dietary minerals[43] (also known as mineral nutrients) are the chemical elements required by living organisms, other than the four elements carbon, hydrogen, nitrogen, and oxygen present in common organic molecules [44]. Examples of mineral elements include calcium, magnesium, potassium, sodium, zinc, and iodine. It is stated that about sixteen chemical elements are required to support human biochemical processes by serving structural and functional roles as well as electrolytes [45]. However, many of these additional elements have no well-defined biochemical function known at present.

The dietary habit in this developing and faster world has greatly made changes in the nutrition transition shifts and in the preset scenario the unprocessed foods present its nutritional quality only when it is consumed in fresh condition [46]. Therefore processed foods are getting attention to be consumed by the peoples because its durability, nutrition content (for e.g. increased by biofortification means) is also comparable to fresh food and easy availability.

All aspects of the production and processing of food have been transformed in the past decades. The availability of fresh and nutrient rich agro foods is a growing problem in many countries and the demand for food is relatively inelastic in manner. These factors have made it necessary to provide new nutritive values to raw agricultural products by its processing and enrichment through available techniques and methods.

\section{Food Processing: Impact on Nutritional Quality and Human Health}

The food processing industry has made much progress since the industrial revolution to keep foods fresh longer and to preserve or alter the nutrient bioavailability state of food [47] Cooling is the primary technology used to maintain freshness, whereas many more technologies have been invented to allow foods to last longer without becoming spoiled. These latter technologies include pasteurization [48], autoclavation [49] drying [50], salting [51], and separation of various components.

Advance techniques of separation such as centrifugation [52] milling and pressing [53] have enabled concentration of particular components of food, yielding flour, oils [54], juices and so on, and even separate fatty acids [55] amino acids [56], vitamins [57], and minerals. Such large scale application of techniques has changed the nutritional content of food, saving certain nutrients while removing others.

Because of reduced nutritional value of raw agricultural and unprocessed foods, processed foods are often 'enriched' or 'fortified' with some of the most critical nutrients like certain vitamins or dietary minerals, during and after processing. Therefore, processed foods have an inferior nutritional profile compared to whole, fresh foods, regarding content of sugar and high gastrointestinal starches, potassium/sodium, vitamins, fiber, and of intact, unoxidized (essential) fatty acids [58].

Some examples are here that greatly support the requirement of food processing: The epidemic history of beriberi disease in people subsisting on polished rice. Removing the outer layer of rice [59] by polishing it with it the essential vitamin thiamine, causing beriberi is an example of the effect of food processing on a population's health.

Another example is from late 19th century associated with the development of scurvy among infants in United States. It turned out that the vast majority of sufferers were being fed milk that had been heat-treated (as suggested by Pasteur) to control bacterial disease. Pasteurization was effective against bacteria, but it destroyed the vitamin C [60]. 
As mentioned, lifestyle- and obesity-related diseases are becoming increasingly prevalent all around the world but there is little doubt about this that the increasingly widespread application of some modern food processing technologies has contributed to this development. Present food processing industry is a major part of modern world economy, and it also influences the political decisions e.g. nutritional recommendations, agricultural subsidising etc.

In any country, effective production of cheap foods with a long shelf-life and high nutrition quality is mostly recommended. In general, whole, fresh or raw agri foods have a relatively short shelf-life and are less profitable to produce and sell than are more processed foods. Thus the consumer is left with the choice between nutritionally weak whole, raw foods, and cheap, usually nutritionally improved processed foods. Because processed foods are often cheaper, more convenient (in purchasing, storage, and preparation), and more available, the consumption of processed foods has been increasing throughout the world because of many nutrition-related health complications with unprocessed foods.

\section{Groups of processed food}

Group I: It contains least processed foods that have been undergone to some processes that does not alter the nutritional properties of the original foods which remain recognizable as such, while aiming to preserve them and make them more accessible, convenient, sometimes safer, and more palatable. Such processes include cleaning, removal of inedible fractions, portioning, refrigeration, freezing, pasteurization, fermenting, pre-cooking, drying, skimming, bottling and packaging. Fresh meat [61] and milk, grains, pulses [62], nuts [63], and fruits [6465], vegetables [66], roots and tubers sold as such, are least processed by various means.

Group II: Extracted Substances from whole food include oils, fats, flours, pastas, starches [67] and sugars. Mostly they are not consumed by themselves. Traditionally they are ingredients used in the domestic preparation and cooking of dishes mainly made up of fresh and minimally processed foods but now the use of group II foods has been transformed. They have become the raw material bases for the third group, of ultra-processed foods [68].

Group III: This group contains the ultra-processed foods that are basically derived from group II ingredients, typically combined with sophisticated use of additives, to make them edible, palatable. In general, these foods are not similar to group I foods, although they may be shaped, labeled and marketed so as to seem wholesome and 'fresh'. Unlike the ingredients included in group II, ultra-processed foods are typically not consumed with or as part of minimally processed foods, dishes and meals. Ultra processed foods have great value of micronutrients and the biofortification techniques are largely applied to this kind of [68].

\section{Some current examples of food processing methods applied for food quality improvement}

Wheat flakes processing: Processed cereals breakfast from wheat flour [69] for example wheat noodles, [70] flakes are eaten more and more frequently by both adults and adolescents, they often contained too much sugars and lead to a high glycemic index (GI) which generally contributes to a more rapid return of the feeling of hunger favoring nibbling in the morning.
A successful attempt was made to reduce the GI and to improve the nutritional quality of standard wheat flakes (SWF) by adding a sourdough prefermentation step, suppressing steam cooking and decreasing the sucrose content (MWF, modified wheat flake).

SWF, MWF, and white-wheat bread (WWB, reference food) were given to some healthy males, at three separate times after that plasma glucose, insulin and ghrelin concentrations were measured. The feeling of hunger was evaluated using a subjective rating scale. Despite its relatively high GI, MWF could provide health benefits by improving the management of hunger feeling in the morning and by moderately improving insulin economy, which could be of interest for type 2 diabetic subjects [71].

Production of active and potentially functional peptides from milk: Bioactive peptides are specific protein fragments that have a positive impact on body conditions and its cellular functionality and they may ultimately have an influence on health also [72]. Milkderived products such as cheese and yogurt have been used as source to study the isolation and activity of peptides with several applications. Currently, the milk whey waste obtained in the production of cheese also represents a protein source from which active peptides could be isolated with regard to their physiological effects have led to the classification of peptides as belonging to the group of ingredients of protein nature, appropriate for use in functional foods or pharmaceutical formulations for the development of human health. Two studies have investigated the treatment of raw milk with nitrogen gas applied to a close system have improved the storage capacity of cold raw milk. [74].

Specially formulated foods for treating moderate malnutrition: Diets based including mainly unprocessed foods do not meet the body requirements of a malnourished child and need to be improved by processing (dehulling, germinating, fermenting), fortification, and adding animal-source foods, e.g., milk, or other specific nutrients. Most supplementary feeding programs for moderately malnourished children supplied with foods which have shortcomings, including too many antinutrients, no milk (important for growth), suboptimal micronutrient content, high bulk, and high viscosity. Thus, for feeding young or malnourished children, fortified blended foods needed with more recent improvements. Based on success with ready-touse therapeutic foods for severe acute malnutrition case treatments, modifying these recipes is also considered. Commodities for reducing child malnutrition should be chosen on the basis of nutritional needs, program circumstances, availability of commodities, and likelihood impact. [85]

Traditionally processed indigenous foods: antioxidant properties: The present study evaluated the flavonoid content, antioxidant [74] as well as type II diabetes-related [75] enzyme inhibition activities of ethanolic extract of certain raw and traditionally processed indigenous food ingredients including cereals, legumes, oil seeds, tubers, vegetables and leafy vegetables, which are commonly consumed by vulnerable groups in Kenya. The vegetables exhibited higher flavonoid content $(50-703 \mathrm{mg} / 100 \mathrm{~g})$ when compared with the grains $(47-343 \mathrm{mg} / 100 \mathrm{~g})$. The ethanolic extract of presently studied food ingredients revealed $33-93 \%$ DPPH radical scavenging capacity, 486-6,389 mmol Fe(II)/g reducing power, 19-43\% a-amylase inhibition activity and 14-68\% a-glucosidase inhibition activity. Roasting of grains and cooking of vegetables were found to be suitable processing methods in preserving the functional properties. Moreover 
Epidemiological evidences have shown inverse correlation between the intakes of dietary components with antioxidant abilities [76-77]. Hence, such viable processing techniques for respective food samples will be considered in the formulation of functional supplementary foods.

Application of pulse electric field (PEF) in inactivation of grape juice spoilage organisms: An experiment based on response surface methodology (RSM) was used to evaluate relationship between the levels of inactivation of microorganisms and the energy applied to the grape juice. Yeast and bacteria were inactivated by the PEF treatments, with reductions that ranged from 2.24 to $3.94 \log$ units. All PEF parameters affected microbial inactivation. The maximum efficacy of the PEF treatment for inactivation of microorganisms in grape juice was observed around $1500 \mathrm{MJ}$ L (-1) for all the microorganisms investigated. The RSM could be used in the fruit juice [78] industry (especially kiwifruit and grape) [79] to optimize the inactivation of spoilage microorganisms by PEF and manage the food spoilage by the microbes that can affect the potential nutrient quality of food.

\section{What next?}

Food is a subject of vital interest to everyone in the world [80]. From the point of view of human health, at present, the most salient division of foods and drinks is in terms of their type, degree and purpose of processing. Three main divisions are specified earlier. For this, most of the dietary advices say to take diets [81] on fresh and minimally processed foods, and on dishes and meals made up from such foods with the addition of refined ingredients extracted from whole foods.

The traditional minimally processed food (group I) diets usually have adequate nutrient and energy density when they contain a varied combination of plant foods [82] (grains, vegetables, pulses, fruits, nuts), only moderate quantities of animal foods, and little salt. Even when the refined ingredients from group II become a substantial part of these traditional diets their overall quality may be still high. Commonly consumed foods with low nutrient density (of protein or vitamins, for instance) or high nutrient density (of saturated fat or sodium, for instance), as well as with extreme energy densities, unbalances the diets and cause either nutritional deficiencies or chronic diseases (for example, obesity, dyslipidaemias and hypertension), or both [83].

If the aim is to understand and improve nutritional quality of any raw food to meet the food security challenges following points could be helpful for food processing industry:

1. Physical characteristics of agricultural products are the most important parameters in design of grading, conveying, processing and packaging systems. [84].

2. Creation of desired food products by new processing technologies based on micro-structure analysis of food

3. Understanding the chemical basis of taste, texture, flavor

4. Understanding the influence of food structure on human physiology and nutrition [85] role of food constituents / food viscosity in energy intake

\section{Preservation of original cell structure}

6. Re-evaluation of existing processes in the light of new knowledge

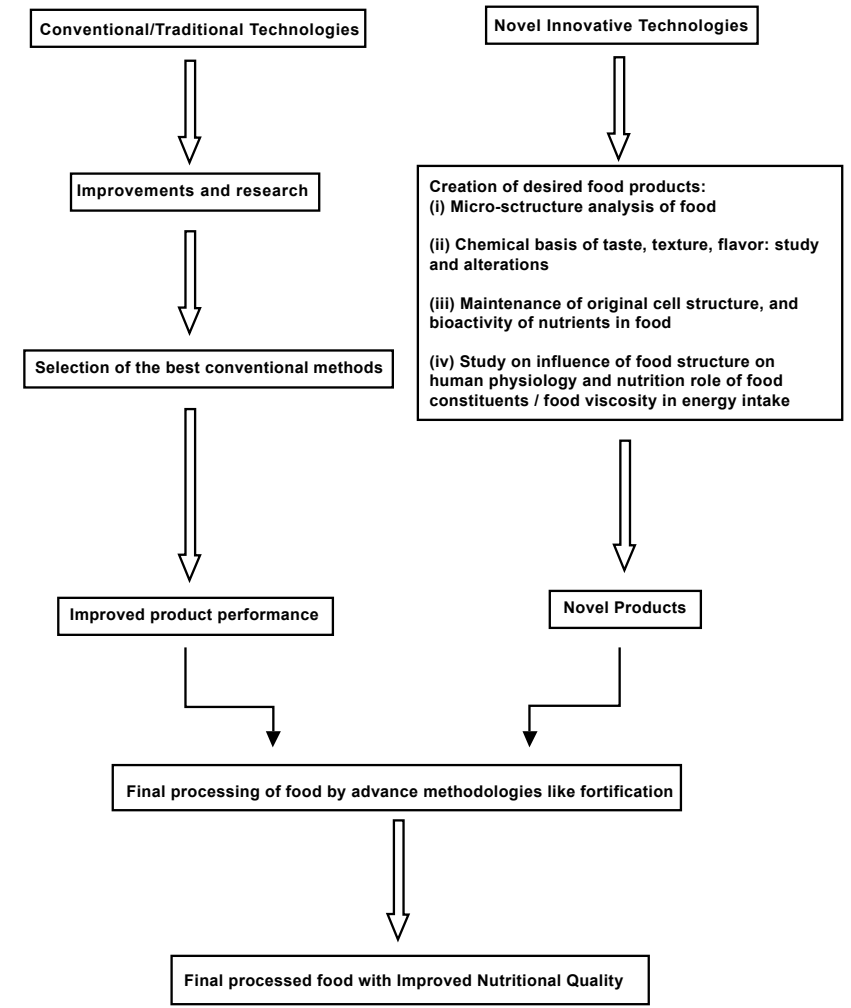

Figure 1: Strategies and trends for Future Food Processing and Production.

Regarding the above mentioned points some strategies and related trends are given in figure 1 that may be helpful for the improvement of the final processed food product quality.

\section{Conclusion}

Nutrition rich food, its availability and food safety are the areas growing worldwide concern on account of their direct bearing on human health. The global food demand depends on processed food products because processing is expected to affect content, activity and bioavailability of nutrients. A few Current examples of processed foods discussed in this review have shown the capability of the food processing in changing the nutritive status of the food. However, the health-promoting capacity of food products strictly depends on their processing history. Traditional technologies such as the use of antimicrobials and thermal processing are efficient in increasing the value of nutrition up to an extent besides the availability of some methods which maintain the level of bioactivity in foods, but they may not be the most effective at improving food safety, to retain the food structure and properties of the ingredients especially in maintaining the food molecular structure.

It is also an important point to think about the number of outbreaks of the over nutrition and obesity that is being observed in recent years due to over consumption of processed foods, but these cases are highly related to 'ready-to-eat' and minimally processed foods. For these facts the innovative technologies and advancements are needed to overcome the above consequences of the food processing. The combinations of traditional and modern food processing methods and research advancements in techniques can provide a major way to enhance food quality, to thrive global food security and safety by improving 
Citation: Satyanarayana SDV, Pavan Kumar P, Amit S, Dattatreya A, Aditya G (2012) Potential Impacts of Food and it's Processing on Global Sustainable Health. J Food Process Technol 3:143. doi:10.4172/2157-7110.1000143

Page 6 of 7

the nutritional composition and use of antimicrobial techniques, maintaining hygiene food products especially the locally grown and familiar foods and their availability to all, that could be able to attract interest of both the developed and developing worlds and also provide the best quality food products that would promise the world from the hazard of global nutrition crisis.

\section{References}

1. Nicoli MC, Anese M, Parpinel M (1999) Influence of processing on the antioxidant properties of fruit and vegetables. Trends in Food Science \& Technology 10: 94-100

2. Whitney Ellie, Rolfes SR (2008) Understanding Nutrition Thomson Wadsworth 154

3. Nikoo M, Ghomi MR, Rahimabadi EZ, Benjakul S, Javadian B (2010) The Effects of Deep-Frying, Refrigerated Storage and Reheating on the Fat Content, Oxidation and Fatty Acid Composition of the Fish Rutilus frisii kutum. J Food Process Technol 1: 103

4. Landmark K, Alm (2006) CS Alpha-linolenic acid, cardiovascular disease and sudden death.

5. Tidsskr Nor Laegeforen 126: 2792-2794

6. Shils et al. (2005) Modern Nutrition in Health and Disease. Lippincott Williams and Wilkins.

7. Seddon JM, Ajani UA, Sperduto RD, Hiller R, Blair N et al. (1994) Dietary carotenoids, vitamins $\mathrm{A}, \mathrm{C}$, and $\mathrm{E}$, and advanced age-related macular degeneration. Eye Disease Case-Control Study Group. JAMA 272: 1413-1420

8. Berg J, Tymoczko JL, Stryer L (2002). Biochemistry. San Francisco W.H. Freeman 603.

9. Food processing

10. FAO/WHO/UNU (2007) Protein And Amino Acid Requirements In Human Nutrition. WHO Press 150

11. STAC - Project Information Center - 03-STAC-01 - Western U. S. Food Processing Efficiency Initiative

12. Xu Y, Bianchini A, Hanna MA (2011) Evaluation of Mold and Mycotoxin Contaminations in Hybrid Hazelnuts Grown in Nebraska. J Food Process Technol 2: 119.

13. Geetanjali Kaushik, Santosh Satya, S.N. Naik (2008) Food processing a tool to pesticide residue dissipation - A review. Food Research International 42: 26-40

14. A. Assimakopoulou (2006) Effect of iron supply and nitrogen form on growth, nutritional status and ferric reducing activity of spinach in nutrient solution culture Scientia Horticulturae 110: 21-29

15. Ross M. Welch, Robin D (2004) Graham Breeding for micronutrients in staple food crops from a human nutrition perspective. J Exp BotFeb 55: 353-64

16. Kizil M, Oz F, Besler HT (2011) A Review on the Formation of Carcinogenic Mutagenic Heterocyclic Aromatic Amines. J Food Process Technol 2: 120

17. R. M. Welch (2002) Impact of mineral nutrients in plants on human nutrition on a worldwide scale Plant Nutrition 92: 284-285

18. Nielsen, Forrest H. USDA, ARS (1999) Ultratrace minerals. Williams \& Wilkins 283-303

19. Popkin BM (2006) Global nutrition dynamics: the world is shifting rapidly toward a diet linked with noncommunicable diseases. Am J Clin Nutr 84: 289-298

20. Lasekan O, Juhari NH, Pattiram PD (2011) Headspace Solid-phase Microextraction Analysis of the Volatile Flavour Compounds of Roasted Chickpea(Cicer arietinum L). J Food Process Technol 2: 112

21. Balaswamy K, Rao PP, Nagender A, Satyanarayana A (2011) Preparation of Sour Grape (Vitis Vinifera) Beverages and Evaluation of their Storage Stability. J Food Process Technol 2: 116

22. Sevda SB, Rodrigues L (2011) Fermentative Behavior of Saccharomyces Strains During Guava (Psidium Guajava L) Must Fermentation and Optimization of Guava Wine Production. J Food Process Technol 2: 118

23. Shukla P, Vishwakarma P (2011) Biochemical and Microbial Examination of Sulphi and Cheend: Two Alcoholic Beverages from Central India. J Nutr Food Sci 1:105

24. Popkin BM (2001) Nutrition in transition: the changing global nutrition challenge Asia Pac J Clin Nutr 10: 13-18

25. Basseri S, Austin RC(2011) Endoplasmic reticulum stress and lipid metabolism mechanisms and therapeutic potential. Biochem Res 2012: 841362

26. Ross M. Welch, Robin D. Graham (2004) Breeding for micronutrients in staple food crops from a human nutrition perspective. Journal of Experimental Botany 55: $353-364$

27. Nutritional Requirements throughout the Life Cycle: Conclusion

28. Durlu-Özkaya F, Özkaya Mt (2011) Oleuropein using as an Additive for Feed and Products used for Humans. J Food Process Technol 2:113

29. Lessons from the food price crisis: 10 actions developing countries should take.

30. Ahmed T, Rahman S, Cravioto A (2009) Oedematous malnutrition. Indian Med Res 130: 651-654.

31. Poor nutrition leaves 200 million children "intellectually stunted"

32. Micronutrient deficiencies

33. Food Insecurity

34. Essential nutrient

35. Atuobi C, Sakyi-Dawson E, Sefa-Dedeh S, Afoakwa EO, Budu AS (2011) Microstructural and Physico-Functional Characterization of Starches from Selected Cowpea (Vigna unguiculata L. Walp.) Varieties Developed for Pest and Disease Resistance. J Nutr Food Sci 1:104

36. NHS Choices:Vitamins and minerals - Others

37. Essential fatty acid

38. The 100 Year Diet - Essential Fatty Acids - Chapter Six

39. Medical Diabetic Recipes Supply

40. Essential amino acid

41. Vitamin

42. Nikoo M, Ghomi MR, Rahimabadi EZ, Benjakul S, Javadian B (2010) The Effects of Deep-Frying, Refrigerated Storage and Reheating on the Fat Content, Oxidation and Fatty Acid Composition of the Fish Rutilus frisii kutum. J Food Process Technol 1: 103

43. Mains RE, Cullen El, May V, Eipper BA (1987) The role of secretory granules in peptide biosynthesis. Ann N Y Acad Sci 493: 278-291

44. Herman RA, Phillips AM, Lepping MD, Sabbatini J (2011) Compositional Safety of DAS-68416-4 (AAD-12) Herbicide-Tolerant Soybean. J Nutr Food Sci 1:103

45. Dietary mineral

46. Bioavailability: How the Nutrients in Food Become Available to Our Bodies

47. Burdge GC, Hoile SP, Uller T, Thomas NA, Gluckman PD et al. (2011) Progressive, Transgenerational Changes in Offspring Phenotype and Epigenotype following Nutritional Transition. PLoS One 6: 28282

48. Bioavailability: How the Nutrients in Food Become Available to Our Bodies

49. Saldaña G, Puértolas E, Monfort S, Raso J, Alvarez I (2011)Defining treatment conditions for pulsed electric field pasteurization of apple juice. Int $\mathrm{J}$ Food Microbiol 151: 29-35

50. Food Waste Characteristics after Autoclaving Treatment (2011) 2nd International Conference on Biotechnology and Food Science, IACSIT Press Singapore

51. Xiao Dong Chen Arun S, Mujumdar (2008) Drying Technologies in Food Processing. Wiley-Blackwell

52. William Albarracín, Iván C. Sánchez, Raúl Grau, José M (2011) Salt in food 
Citation: Satyanarayana SDV, Pavan Kumar P, Amit S, Dattatreya A, Aditya G (2012) Potential Impacts of Food and it's Processing on Global Sustainable Health. J Food Process Technol 3:143. doi:10.4172/2157-7110.1000143

processing; usage and reduction: a review. Barat International Journal of Food Science \& Technology. 46: 7, 1329-1336.

53. Centrifugation

54. Brandolini A, Hidalgo A (2011) Wheat germ: not only a by-product. Int J Food Sci Nutr

55. Matthäus B, Özcan Mm (2011) Determination of Fatty Acid, Tocopherol, Stero Contents and 1,2- and 1,3-Diacylglycerols in Four Different Virgin Olive Oil. J Food Process Technol 2: 117

56. Vafeiadou K, Weech M, Sharma V, Yaqoob P, Todd S et al. (2011) A review of the evidence for the effects of total dietary fat, saturated, monounsaturated and $n-6$ polyunsaturated fatty acids on vascular function, endothelial progenitor cells and microparticles. Br J Nutr. 19: 1-22

57. Rajapakse N, Kim SK (2011) Nutritional and digestive health benefits of seaweed. Adv Food Nutr Res 64: 17-28

58. Salvia-Trujillo L, Morales-de la Peña M, Rojas-Graü A, Martín-Belloso O (2011) Changes in water-soluble vitamins and antioxidant capacity of fruit juice-milk beverages as affected by high-intensity pulsed electric fields (HIPEF) or heat during chilled storage. J Agric Food Chem. 59: 10034-10043

59. Karr JE, Alexander JE, Winningham RG (2011) Omega-3 polyunsaturated fatty acids and cognition throughout the lifespan: a review. Nutr Neurosci 14: 216225

60. Nagendra Prasad MN, Sanjay KR, Shravya Khatokar M, Vismaya MN, Nanjunda Swamy S (2011) Health Benefits of Rice Bran - A Review. J Nutr Food Sci 1: 108

61. Food processing

62. Zaidi R, Rawat PR (2011) Identification of Heterocyclic Amines in Indian Home Cooked and Commercially Available Meat Foods. J Nutr Food Sci 1:107

63. Mangaraj S, Singh KP (2011) Milling Study of Multiple Pulses Using Ciae Dha Mill For Optimal Responses. J Food Process Technol 2:110

64. Khodabakhshian R, Bayati MR (2011) Investigation into the Effects of Impeller Vane Patterns and Pistachio Nut Size on Hulling Efficiency of Pistachio Nuts using A Centrifugal Huller. J Food Process Technol 2: 115

65. Tortoe C, Orchard J, Beezer A (2011) Multilinear Regression Approach in Predicting Osmo-Dehydration Processes of Apple, Banana and Potato. J Food Process Technol 2: 122

66. Kammoun Bejar A, Kechaou N, Boudhrioua Mihoubi N (2011) Effect of Microwave Treatment On Physical and Functional Properties of Orange (Citrus Sinensis) Peel and Leaves. J Food Process Technol 2: 109

67. Abano EE, Ma H, Qu W (2011) Influence of Air Temperature on the Drying Kinetics and Quality of Tomato Slices. J Food Process Technol 2: 123

68. Nautiyal OP (2011) Hydrocolloids, Modified Hydrocolloids as Food Recipes and Formulating Agents. J Food Process Technol 2: 111

69. Monteiro CA, Levy RB, Claro RM, de Castro IR, Cannon G (2011) Increasing consumption of ultra-processed foods and likely impact on human health: evidence from Brazil. Public Health Nutr 14: 5-13

70. Khan MA, Semwal AD, Sharma GK, Mahesh C, Nataraj S, et al. (2011) Development and Evaluation of Long Shelf-Life Ambient Stable Chapaties Without The Use of Chemical Preservatives. J Food Process Technol 2: 107

71. Thao HM, Noomhorm A (2011) Physiochemical Properties of Sweet Potato and Mung Bean Starch and Their Blends for Noodle Production. J Food Process Technol 2: 105

72. Bawadi HA, Ammari F, Abu-Jamous D, Khader YS, Bataineh S (2011) Food insecurity is related to glycemic control deterioration in patients with type 2 diabetes. Clin Nutr

73. Settanni L, Moschetti G (2010) Non-starter lactic acid bacteria used to improve cheese quality and provide health benefits. Food Microbiol 27: 691-697.

74. Munsch-Alatossava P, Gursoy O, Alatossava T (2010) Improved Storage of Cold Raw Milk by Continuous Flushing of N2 Gas Separated from Compressed Air: A Pilot Scale Study. J Food Process Technol 1: 101
75. Raphael MO, Lucy OF (2011) Influences of Pleurotus Sajor-caju Diets on Performance and Biochemical Parameters in Experimental Rats. J Nutr Food Sci 1: 112

76. Huffman FG, Vaccaro JA, Nusrath NS, Zarini GG (2011) The Effect of Carbohydrate Amount, Quality and Type on Arterial Pulse Pressure in CubanAmericans with and Without Type 2 Diabetes. J Nutr Food Sci 1: 106

77. Adefegha SA, Oboh G (2011) Water Extractable Phytochemicals from Some Nigerian Spices Inhibit Fe2+- Induced Lipid Peroxidation in Rat's Brain - In Vitro. J Food Process Technol 2: 104

78. Turconi G (2011) Healthy Aging: Nutritional Intervention to Improve and Extend Quality of Life among Older People. J Nutr Food Sci 1: e101

79. Akhtar M, Chan P, Safriani N, Murray B, Clayton G (2011) Concentration of Apple Juice Using Spinning Disc Reactor Technology. J Food Process Technol 2: 108

80. Goula AM, Adamopoulos KG (2011) Rheological Models of Kiwifruit Juice for Processing Applications. J Food Process Technol 2: 106

81. Syed HM, Jadhav BA, Salve RV (2011) Studies on Preparation of Low Calorie Cake using Pearl Millet (Bajra) Maltodextrin. J Food Process Technol 2: 125

82. Jasour MS, Rahimabadi EZ, Ehsani A, Rahnama M, Arshadi A (2011) Effects of Refrigerated Storage on Fillet Lipid Quality of Rainbow Trout (Oncorhynchus Mykiss) Supplemented by a-Tocopheryl Acetate Through Diet and Direct Addition after Slaughtering. J Food Process Technol 2: 124

83. Aberoumand A (2011) Protein, Fat, Calories, Minerals, Phytic acid and Phenolic In Some Plant Foods Based Diet. J Food Process Technol 2: 114

84. Brisbois TD, Farmer AP, McCargar LJ (2011) Early markers of adult obesity: a review. Obes Rev.

85. Mansouri YS, Khazaei J, Hassan Beygi SR, Mohtasebi SS (2010) Statistical Modeling of Pomegranate (Punica granatum L.) Fruit with Some Physical Attributes. J Food Process Technol 1: 102.

86. De Pee S, Bloem MW (2009) Current and potential role of specially formulated foods and food supplements for preventing malnutrition among 6- to 23-monthold children and for treating moderate malnutrition among 6- to 59-month-old children. Food Nutr Bull. 30: 434-463. 